\title{
ASSESSMENT SALES RATIO, SUATU ALAT PENGUKUR KINERJA PENETAPAN NPOP \\ (Studi di Desa Ambarketawang, Sleman) \\ Asih Retno Dewi ${ }^{1}$
}

\begin{abstract}
Performance measurement in determining the Tax Object Acquisition Value as the basis for the imposition of duties on Acquisition of Land and Building Rights is conducted by analysis tool using assessment sales ratio (ASR). ASR analysis aims to determine the level of conformity of Tax Object Aceuisition Value (NPOP) to land market value to determine whether Tax Object Aceuisition Value is in proportion, experienced under assessment, or over- assessment. Moreover, this technique also aims to measure diversity (variability) to account the level of fairness of Tax Object Aceuisition Value as the bases of Duty on Acquisition of Land and Building Rights (BPHTB). The results shows that the determination of Tax Object Acquisition Value as the bases to determine BPHTB in Ambarketawang is lower compared to its property market value (under-assessment occurred). The variability on the determination of Tax Object Sales Value NPOP as the bases to determine BPHTB in Ambarketawang village is high, implies that it does not indicate good uniformity.
\end{abstract}

Keywords: Tax Object Acquisition Value, Property Market Value, Assessment Sales Ratio

Intisari: Pengukuran kinerja dalam penetapan Nilai Perolehan Objek Pajak (NPOP) sebagai dasar pengenaan Bea Perolehan Hak atas Tanah dan Bangunan (BPHTB) dilakukan dengan alat analisis assessment sales ratio(ASR). Analisis ASR bertujuan untuk mengetahui tingkat kesesuaian NPOP terhadap nilai pasar tanah apakah dalam penetapan NPOP sudah proporsional, terjadi under assessment, atau over assessment. Selain itu, juga bertujuan untuk mengukur keberagaman (variabilitas) NPOP sehingga diketahui tingkat keadilan penetapan NPOP sebagai dasar pengenaan BPHTB. Hasil penelitian menunjukkan bahwa penetapan NPOP sebagai dasar pengenaan BPHTB di Desa Ambarketawang masih relatif rendah dibandingkan dengan nilai pasar tanahnya (terjadi underassessment).Tingkat keberagaman dalam penetapan NIOP sebagai dasar penentuan BPHTB di Desa Ambarketawang sangat tinggi atau tidak menunjukkan keseragaman yang baik.

Kata kunci: NPOP, Nilai Pasar Tanah, Assessment Sales Ratio

\section{A. Pendahuluan}

Terbitnya Undang-Undang Nomor 28 Tahun 2009 tentang Pajak Daerah dan Retribusi Daerah berimplikasi semakin menguatnya kewenangan pemerintah daerah dalam mengelola pajak dan retribusi daerah. Salah satu dari 1 (sebelas) jenis pajak yang dikelola kabupaten/kota adalah Bea Perolehan Hak atas Tanah dan Bangunan (BPHTB). Sejak tanggal 1 Januari 2011, Pemerintah Daerah Kabupaten Sleman telah menerima pengalihan pengelolaan BPHTB dari pemerintah pusat berdasarkan

\footnotetext{
${ }^{1}$ Peneliti di Pusat Penelitian dan Pengabdian kepada Masyarakat,STPN.E-mail: reredewir503@gmail.com
}

Peraturan Daerah (Perda) Kabupaten Sleman Nomor 14 Tahun 2010 tentang Bea Perolehan Hak atas Tanah dan Bangunan.

Letak Kabupaten Sleman sangat strategis karena berbatasan dengan Kota Yogyakarta dan beberapa kabupaten di Provinsi Jawa Tengah. Data BPS Kabupaten Sleman Tahun 2013 menyebutkan pertumbuhan penduduk per tahun sebesar o,73 persen sehingga dapat dikategorikan daerah dengan pertumbuhan penduduk yang relatif tinggi. Kecenderungan ini disebabkan fungsi Kabupaten Sleman sebagai penyangga Kota Yogyakarta, daerah tujuan untuk melanjutkan pendidikan, dan daerah pengembangan pemukiman/perumahan sehingga 
pertumbuhan penduduk yang terjadi lebih banyak didorong oleh faktor migrasi penduduk bukan oleh tingkat kelahiran yang tinggi. (Rencana Kerja Pengembangan Daerah/RKPD Kabupaten Sleman Tahun 2013: II-8). Sebagai daerah penyangga Kota Yogyakarta, Kabupaten Sleman mengalami pertumbuhan sektor properti yang pesat. Hal ini menjadikan potensi yang cukup besar untuk dimanfaatkan sebagai sumber pendapatan bagi daerah melalui pemungutan pajak tanah seperti BPHTB.

Pasal 7 ayat (1) Peraturan Daerah Kabupaten Sleman Nomor 14 Tahun 2010 tentang BPHTB menyebutkan bahwa dasar pengenaan BPHTB adalah Nilai Perolehan Objek Pajak (NPOP). Selanjutnya pada ayat (3) disebutkan jika NPOP tidak diketahui atau lebih rendah dari Nilai Jual Objek Pajak (NJOP) yang digunakan dalam pengenaan Pajak Bumi dan Bangunan (PBB) pada tahun terjadinya perolehan, maka dasar pengenaan yang dipakai adalah NJOP PBB tersebut. NPOP tersebut adalah harga transaksi atau nilai pasar. NPOP tidak diketahui dalam Pasal 7 tersebut dimaksudkan untuk perolehan hak yang tidak melibatkan nilai uang misalnya karena waris atau hibah; atau perolehan hak karena peralihan yang tidak wajar misalnya karena adanya hubungan istimewa (antara lain peralihan hak antar saudara, perusahaan dengan anak perusahaan), atau peralihan hak karena lelang dimana harga yang didapat lebih rendah dari nilai pasar.

M. Danang (diskusi, 23 Februari 2015) menyatakan bahwa pemungutan BPHTB di Kabupaten Sleman dewasa ini masih menemui beberapa masalah diantaranya ketidaksesuaian NPOP terhadap harga transaksi maupun nilai pasar tanah. BPHTB adalah salah satu jenis pajak yang dilaporkan sendiri oleh wajib pajak, bukan berdasarkan surat ketetapan pajak yang dibuat oleh pemerintah sebagaimana PBB. NPOP yang dilaporkan oleh wajib pajak rentan dimanipulasi. Nampaknya ketentuan dalam Pasal 7 ayat (1) Peraturan Daerah Kabupaten Sleman Nomor 14 Tahun 2010 yang merupakan celah hukum tersebut dimanfaatkan oleh PPAT dan wajib pajak untuk tidak melaporkan besarnya NPOP yang sebenarnya. NJOP PBB yang digunakan sebagai dasar penetapan NPOP menyebabkan penerimaan dari BPHTB lebih rendah dari yang seharusnya. Hal ini disebabkan karena NJOP yang terlalu rendah dari nilai pasar. NJOP pada dasarnya ditujukan untuk pengenaan PBB dimana melibatkan masyarakat luas yang relatif berbeda kondisinya sehingga ditetapkan lebih rendah dari nilai pasar.

Beberapa kajian yang sejenis dengan tulisan ini pernah dilakukan baik di Indonesia maupun di luar negeri. Hodge mengevaluasi ketidakadilan vertikal dan horisontal yang dilakukan oleh para penilai dan pemilik properti di Kota Detroit. Penelitian tersebut menunjukkan bahwa banyak terjadi praktek penilaian yang tidak akurat dan kredibel sehingga menghasilkan ketidaksamaan nilai yang signifikan. Terdapat perbedaan yang cukup besar antara harga jual properti yang sebenarnya dengan ketetapan nilai yang dihasilkan oleh para penilai, hal ini mengakibatkan adanya potensi kehilangan pajak yang besar sehingga merugikan pemerintah.

Sutrisna (2013) melakukan penelitian serupa di Kota Denpasar. Penelitian ini menyebutkan bahwa Assessment Sales Ratio (ASR) pada daerah yang diuji masih di bawah standar yang ditetapkan pemerintah serta tingkat keseragaman penentuan NPOP dari pergerakan indikasi nilai pasar properti tergolong rendah.

Penelitian Strauss (2014) bertujuan untuk menguji tingkat keseragaman dan regresivitas pajak properti di Piladelphia. Tingkat akurasi berdasarkan hasil penelitian menunjukkan penilaian yang dilakukan sangat tidak seragam dan sangat regresif atau terdapat ketidakseragaman yang ekstrim sehingga Strauss mengusulkan untuk dilakukan penilaian ulang terhadap dasar penetapan pajak properti. Hal ini sesuai dengan pendapat dari Hartoyo bahwa salah satu manfaat dari hasil studi ASR dapat digunakan untuk penentuan lokasi/daerah yang perlu dilakukan penilaian ulang (revaluation) dengan analisis variabilitas.

Kuswanto (2014) meneliti tentang akurasi NPOP 
terhadap nilai pasardi Kecamatan PurwokertoTimur, Banyumas. Akurasi NPOP di wilayah penelitian masih relatif rendah dibandingkan dengan nilai pasar propertinya sehingga mengindikasikan terjadi under assessment dalam penetapan NPOP. Variabilitas nilai ASR NJOP dengan nilai pasar properti masih relatif tinggi, menunjukkan tingkat keseragaman yang rendah dan terjadi regresivitas dalam penetapan NJOP sebagai dasar pengenaan BPHTB.

Mengacu pada penelitian-penelitian yang terdahulu maka penelitian ini mencoba untuk mereplikasi penelitian-penelitian tersebut. Akan tetapi, ada beberapa perbedaan dengan penelitian sebelumnya yaitu lokasi penelitian, objek penelitian, periode penelitian, dan model yang digunakan. Berbeda dengan penelitian Hodge yang mengggunakan analisi regresi, penelitian ini menggunakan analisis ASR. Penelitian Sutrisna menggunakan standar yang ditetapkan pemerintah dalam hal ini Menteri Keuangan RI, sedangkan penelitian ini berdasarkan standar yang ditetapkan International Association of Assessing Officers (IAAO). Hampir mirip dengan penelitian Strauss dan Kuswanto, penelitian ini lebih rinci dalam tahapan analisis ASR yang dilakukan untuk mengetahui berapa rasio antara penentuan NPOP terhadap nilai pasar properti.

Penelitian ini dilakukan di Desa Ambarketawang, Kecamatan Gamping, Kabupaten Sleman pada Tahun 2015 dengan didasarkan atas pertimbangan bahwa Desa Ambarketawang letaknya relatif dekat dengan Kota Yogyakarta dan mengalami perkembangan wilayah yang cukup pesat. Desa Ambarketawang berjarak 4,5 kilometer dari pusat Kota Yogyakarta serta dilalui jaringan jalan arteri yang membentang dari Utara-Selatan (Ring Road Barat) dan dari Timur-Barat (Jalan Yogyakarta-Wates, yang merupakan jalur utama Yogyakarta-PurwokertoJakarta). Desa Ambarketawang, tepatnya Dusun Patukan merupakan pusat kegiatan di Kecamatan Gamping. Letaknya yang strategis dan merupakan kawasan penyangga pengembangan Kota Yogyakarta ke arah Barat sehingga membuat desa ini berkembang pesat di bidang ekonomi, perindustrian, pendidikan, perdagangan, dan kependudukan.

Metode analisis data yang dilakukan meliputi:

1. Penghitungan nilai pasar tanah.

Penghitungan nilai pasar tanah dilakukan terhadap tanah yang ditetapkan sebagai objek penilaian dengan menggunakan pendekatan pasar. Pendekatan ini mempertimbangkan harga transaksi tanah yang identik atau sebanding yang baru terjadi atau dapat pula mempertimbangkan harga-harga penawaran tanah yang sebanding dengan objek penilaian. Apabila terdapat perbedaan dengan transaksi sebenarnya maka perlu dilakukan penyesuaian atas informasi harga transaksi/penawaran.

2. Pengukuran tingkat penilaian NPOP terhadap nilai pasar tanah.

Pengukuran ini dilakukan dengan menggunakan pengujian ASR. Studi ASR menurut Eckert et al. (1990 dalam Kuswanto 2014: 32) setidaknya dapat melihat dua aspek utama dalam pengukuran akurasi penilaian yaitu tingkat penilaian dan keseragaman (uniformity). Tingkat penilaian terkait dengan rasio secara keseluruhan dari sekelompok tanah yang telah dinilai. Keseragaman penilaian terkait dengan kewajaran dan kesamaan atau keadilan terhadap tanah secara individual.

Dalam penilaian massal yang sering dilakukan dalam penilaian pajak tanah, nilai pajak tanah yang ditetapkan tidak selalu sama dengan indikatorindikator nilai pasarnya. Namun jumlah nilai pajak tanah yang lebih tinggi dari nilai pasar (over assessment) akan seimbang dengan jumlah nilai pajak tanah yang lebih rendah dari pasar (under assessment), sehingga secara keseluruhan rasio akan berada pada kisaran 100 persen. Dalam kondisi ini tingkat penetapan pajak tanah berada level proporsional terhadap nilai pasarnya, dan dapat dikatakan akurat.

Keseragaman penelian terkait dengan kewajaran dan kesamaan atau keadilan terhadap tanah secara 
individual. Keseragaman dalam hal ini menunjukkan bahwa nilai pajak tanah ditetapkan dalam nilai yang sama dalam suatu kelompok atau zona yang memiliki karakteristik kelas, lokasi ataupun lingkungan yang sejenis atau sebanding. Jika dikaitkan dengan rasio nilai pajak terhadap nilai pasar, nilai pajak masingmasing tanah dalam suatu kelompok tanah ditetapkan dalam tingkat rasioyang sama dari nilai pasarnya. Keseragaman yang menunjukkan keadilan ini bukan hanya ditunjukkan dalam satu kelompok tanah yang sama saja, namun juga keseragaman atau keadilan antarkelompok tanah yang berbeda (Eckert et al., 1990 dalam Kuswanto, 2014: 33).

Standar assessment level yang dijadikan acuan dalam pengukuran ASR ini adalah standar yang ditetapkan oleh International Association of Assessing Officers (IAAO). Novie (2010: 4), mengungkapkan bahwa IAAO yang berpusat di Amerika Serikat adalah sebuah organisasi internasional yang melakukan penelitian, menyelenggarakan pendidikan, menetapkan standar penilaian administrasi, menyediakan jasa profesi penilaian tanah, dan hal lain yang berhubungan dengan pajak tanah. IAAO telah memberikan rekomendasi ukuran ASR yang dapat diterima agar tercipta keseragaman dan keadilan pajak tanah bagi negara-negara di dunia. Standar assessment level untuk tahun 2013 dapat dilihat pada Tabel 1 sebagai berikut.

Tabel 1. Standar Assessment Level

\begin{tabular}{|l|l|c|c|}
\hline \multicolumn{1}{|c|}{$\begin{array}{c}\text { Jenis Tanah } \\
\text { (Umum) }\end{array}$} & \multicolumn{1}{|c|}{ Jenis Tanah (Spesefik) } & $\begin{array}{c}\text { Nilai } \\
\text { Tendensi } \\
\text { Sentral }\end{array}$ & $\begin{array}{c}\text { Rentang } \\
\text { COD }\end{array}$ \\
\hline $\begin{array}{l}\text { Residensial } \\
\text { (termasuk } \\
\text { kondominium } \\
\text { perumahan) }\end{array}$ & $\begin{array}{l}\text { Daerah yang lebih baru } \\
\text { atau lebih homogen }\end{array}$ & $0,90-1,10$ & $5,0-10,0$ \\
\hline Residensial & $\begin{array}{l}\text { Daerah heterogen yang } \\
\text { lebih tua }\end{array}$ & $0,90-1,10$ & $5,0-15,0$ \\
\hline $\begin{array}{l}\text { Residensial } \\
\text { lainnya }\end{array}$ & $\begin{array}{l}\text { Pedesaan, musiman, } \\
\text { rekresasi, perumahan } \\
\text { produksi, 2-4 perumahan } \\
\text { unit keluarga }\end{array}$ & $0,90-1,10$ & $5,0-20,0$ \\
\hline $\begin{array}{l}\text { Tanah } \\
\text { menghasilkan } \\
\text { pendapatan }\end{array}$ & $\begin{array}{l}\text { Sifat daerah yang lebih } \\
\text { besar diwakili oleh } \\
\text { sampel yang besar }\end{array}$ & $0,90-1,10$ & $5,0-15,0$ \\
\hline $\begin{array}{l}\text { Tanah } \\
\text { menghasilkan } \\
\text { pendapatan }\end{array}$ & $\begin{array}{l}\text { Sifat daerah yang kecil } \\
\text { diwakili oleh sampel yang } \\
\text { kecil }\end{array}$ & $0,90-1,10$ & $5,0-20,0$ \\
\hline Lahan kosong & & $0,90-1,10$ & $5,0-25,0$ \\
\hline $\begin{array}{l}\text { Real dan personal } \\
\text { tanah lainnya }\end{array}$ & $\begin{array}{c}\text { Bervariasi } \\
\text { tergantung } \\
\text { kondisi lokal }\end{array}$ \\
\hline
\end{tabular}

Sumber: IAAO (2013:17)
Elriza dalam Jurnal EMBA (2013: 1377) menyatakan bahwa Standard on Ratio Studies IAAO 2010 memberikan rekomendasi bahwa tingkat ASR untuk semua objek pajak dalam suatu daerah seharusnya berada dalam kisaran 10 persen dari tingkat rasio yang diinginkan yaitu antara 90\% - 110\%. Standar pengukuran akurasi penetapan objek pajak terhadap nilai pasar menurut IAAO tersebut adalah:

1. jika mean/median > 1,10 (110\%) berarti over-assessment;

2. jika mean/median < 0,90 (90\%) berarti underassessment;

3. jika mean $/ w$-mean $>1,10(110 \%)$ berarti terjadi regresivitas;

4. jika mean/w-mean < o,90 (90\%) berarti terjadi progresivitas.

Dalam hal ini, mean atau nilai rerata adalah jumlah keseluruhan pengamatan dibagi dengan jumlah pengamatan. Median atau nilai tengah diukur dengan cara mengurutkan data semua sampel dari nilai rasio yang paling kecil sampai yang paling besar kemudian ditentukan nilai tengahnya. Weighted mean ( $w$-mean) atau rerata tertimbang merupakan rerata yang dilakukan dengan pembobotan. Dalam penelitian ini rerata tertimbang adalah jumlah nilai NPOP dibagi dengan jumlah nilai pasar properti.

Under assessment adalah penetapan nilai yang lebih rendah dari nilai pasarnya, sebaliknya over assessment adalah penetapan nilai yang lebih tinggi dari nilai pasarnya. Progresivitas adalah terjadinya kecenderungan naik dalam arti bahwa semakin tinggi nilai properti, maka rasio antara hasil penetapan dibandingkan dengan nilai pasarnya semakin meningkat. Regresivitas atau kecenderungan turun di mana semakin tinggi nilai properti, maka rasio antara hasil penetapan dibandingkan dengan nilai pasarnya semakin menurun.

\section{B. Nilai Perolehan Objek Pajak untuk Tanah Kosong di Ambarketawang}

Analisis dilakukan pada data pembayaran BPHTB untuk tanah kosong yang peralihannya terjadi 
melalui proses jual beli. Pertimbangan ini didasarkan pada tingkat kesulitan untuk memperoleh data karakteristik bangunan dan data pembanding yang sesuai di lokasi penelitian. Data yang digunakan dalam analisis adalah data pembayaran BPHTB untuk tanah kosong yang terjadi pada bulan Januari sampai dengan Desember 2014.

Data objek pembayaran BPHTB berdasarkan NPOP Desa Ambarketawang untuk tanah kosong selama Tahun 2014 diperoleh dari Dinas Pendapatan Daerah Kabupaten Sleman sebanyak 99 (sembilan puluh sembilan) data transaksi sebagai

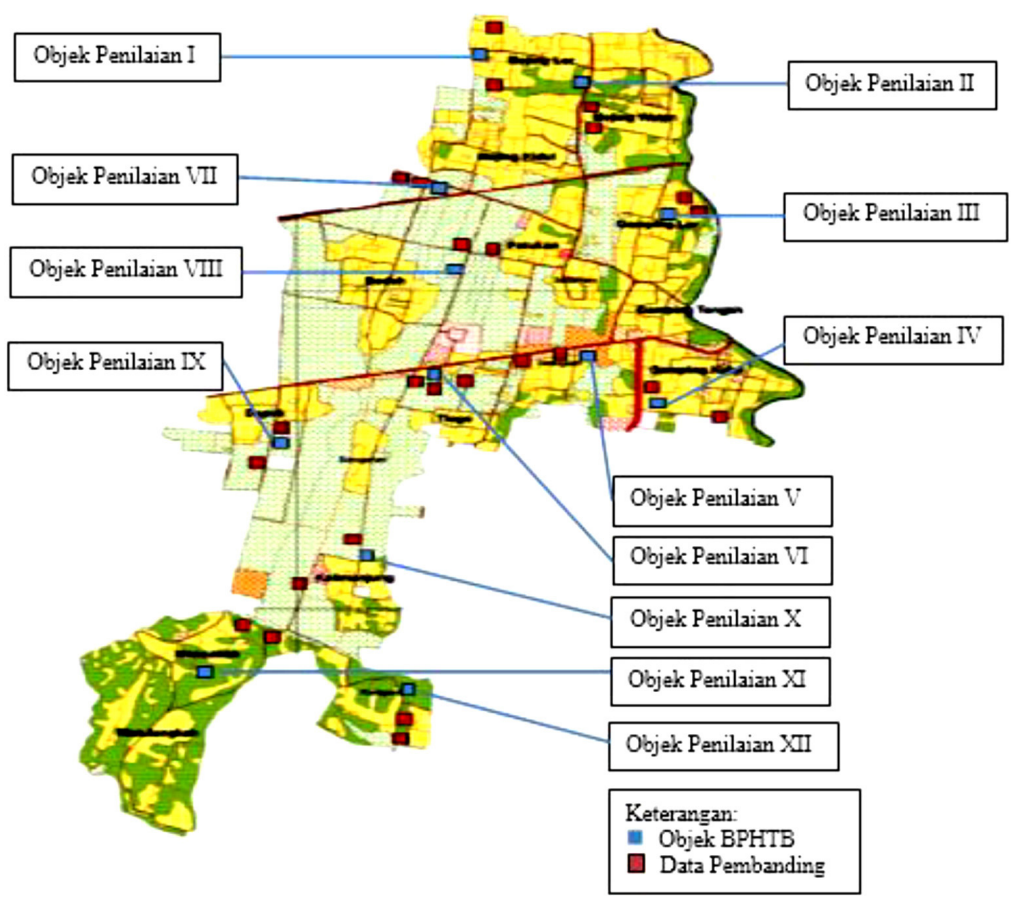
populasi dalam penelitian ini. Data objek penilaian atau sampel dipilih berdasarkan ketersediaan data pembanding berupa penawaran tanah kosong. Gambar I. Sebaran Objek Penilaian (Sampel). Sumber: Pemerintahan Desa Ambarketawang diolah, 2015 Objek penilaian dan data pembanding harus identik atau sebanding. Antara objek penilaian dengan data pembanding harus terletak pada daerah yang mempunyai peruntukan yang sama, mempunyai banyak faktor kesamaan, serta data pembandingyang tersedia harus relatif baru/transaksi yang terjadi belum lama berlangsung. Berdasarkan syarat-syarat tersebut selanjutnya dipilih 12 (dua belas) data sampel penelitian sebagaimana disajikan dalam Tabel 2.

Tabel 2. Data Objek Penilian (Sampel)

\begin{tabular}{|c|l|l|r|r|r|}
\hline No & $\begin{array}{c}\text { Objek } \\
\text { Penilaian }\end{array}$ & $\begin{array}{c}\text { Alamat Objek } \\
\text { Penilaian }\end{array}$ & $\begin{array}{c}\text { Luas Tanah } \\
\left(\mathrm{m}^{2}\right)\end{array}$ & NPOP (Rp) & $\begin{array}{c}\text { NPOP } / \mathrm{m}^{2} \\
(\mathrm{Rp})\end{array}$ \\
\hline 1 & I & Mejing Lor & 106 & $80.000 .000,00$ & $755.000,00$ \\
\hline 2 & II & Mejing Lor & 411 & $308.250 .000,00$ & $750.000,00$ \\
\hline 3 & III & Gamping Lor & 194 & $100.000 .000,00$ & $515.000,00$ \\
\hline 4 & IV & Gamping Kidul & 98 & $68.600 .000,00$ & $700.000,00$ \\
\hline 5 & V & Gamping Tengah & 211 & $194.120 .000,00$ & $920.000,00$ \\
\hline 6 & VI & Depok & 207 & $190.000 .000,00$ & $918.000,00$ \\
\hline 7 & VII & Mejing Kidul & 564 & $226.164 .000,00$ & $401.000,00$ \\
\hline 8 & VIII & Mejing Kidul & 478 & $100.000 .000,00$ & $209.000,00$ \\
\hline 9 & IX & Depok & 1238 & $140.000 .000,00$ & $113.000,00$ \\
\hline 10 & X & Kalimanjung & 596 & $120.000 .000,00$ & $201.000,00$ \\
\hline 11 & XI & Mancasan & 300 & $80.700 .000,00$ & $269.000,00$ \\
\hline 12 & XII & Mancasan & 214 & $64.000 .000,00$ & $299.000,00$ \\
\hline
\end{tabular}

Sumber: Data Sekuder diolah, 2015

Sebaran objek penilaian beserta data pembandingnya dapat dilihat pada Gambar 1.

\section{Penghitungan Nilai Pasar Tanah di Desa Ambarketawang}

Penghitungan indikasi nilai pasar tanah ini dilakukan terhadap tanah yang ditetapkan sebagai sampel objek penilaian dengan menggunakan pendekatan perbandingan data pasar. Penilaian atas suatu tanah dilakukan dengan membandingkan secara langsung tanah yang dinilai dengan data tanah yang sejenis. Pendekatan ini mempertimbangkan harga transaksi tanah yang identik atau sebanding yang belum lama berlangsung. Apabila transaksi tanah yang terjadi hanya sedikit maka dapat mempertimbangkan harga-harga penawaran dari tanah yang sebanding dengan tanah objek penilaian. Terhadap data pembanding tersebut selanjutnya dilakukan penyesuaian atas faktor-faktor yang mempengaruhi nilai bila terdapat perbedaan dengan tanah objek penilaian untuk mengetahui indikasi nilai pasar tanah objek penilaian. Secara ringkas, indikasi nilai tanah objek penilaian yang diestimasi menggunakan pendekatan pasar merupakan jumlah dari harga penawaran tanah-tanah pembanding 
dengan penyesuaian-penyesuaian (adjustment). Penelitian ini menggunakan data pembanding yang didapatkan dari iklan penawaran di internet. Hasil penghitungan indikasi nilai pasar tanah untuk Objek Penilaian I dapat dilihat pada Tabel 3.

Tabel 3. Penghitungan Indikasi Nilai Pasar Tanah Objek Penilaian I

\begin{tabular}{|c|c|c|c|c|c|}
\hline Karakteristik & \multicolumn{2}{|c|}{ Pembanding I } & \multicolumn{2}{|c|}{ Pembanding II } & $\begin{array}{c}\text { Objek } \\
\text { Penilaian }\end{array}$ \\
\hline Alamat & \multicolumn{2}{|c|}{ Mejing Lor } & \multicolumn{2}{|c|}{ Mejing Lor } & Mejing Lor \\
\hline Harga Penawaran (Rp) & \multicolumn{2}{|c|}{198.000 .000} & \multicolumn{2}{|c|}{640.000 .000} & \\
\hline Luas $\left(\mathrm{m}^{2}\right)$ & \multirow{2}{*}{\multicolumn{2}{|c|}{$\begin{array}{r}110 \\
\end{array}$}} & \multicolumn{2}{|r|}{400} & 106 \\
\hline Status Kepemilikan & & & \multicolumn{2}{|c|}{ Hak Milik } & Hak Milik \\
\hline Peruntukan & \multicolumn{2}{|c|}{ Pemukiman } & \multicolumn{2}{|c|}{ Pemukiman } & Pemukiman \\
\hline $\begin{array}{l}\text { Jarak dari Pasar Gamping } \\
\text { (m) }\end{array}$ & \multicolumn{2}{|r|}{1.500} & \multicolumn{2}{|r|}{2.500} & 2.620 \\
\hline $\begin{array}{l}\text { Jarak dari Jl Gamping- } \\
\text { Sidoarum }(\mathrm{m})\end{array}$ & \multicolumn{2}{|r|}{300} & \multicolumn{2}{|r|}{500} & 572 \\
\hline \multicolumn{6}{|l|}{ Adjustment/Penyesuaian } \\
\hline Indikasi Nilai Tanah (Rp) & \multicolumn{2}{|l|}{178.200 .000} & \multicolumn{2}{|l|}{ 576.000.000 } & \\
\hline $\begin{array}{l}\text { Indikasi Nilai Tanah } / \mathrm{m}^{2} \\
\text { (Rp) }\end{array}$ & 1.620 .000 & & 1.440 .000 & & \\
\hline Luas & o & o & $-3 \%$ & -43.200 & $\mathrm{o}$ \\
\hline Status Kepemilikan & o & o & o & o & o \\
\hline Peruntukan & o & o & o & o & o \\
\hline Jarak dari Pasar Gamping & $-2 \%$ & -32.400 & o & $\mathrm{o}$ & $\mathrm{o}$ \\
\hline $\begin{array}{l}\text { Jarak dari Jl Gamping- } \\
\text { Sidoarum }\end{array}$ & o & o & o & o & o \\
\hline Total Penyesuaian & $-2 \%$ & -32.400 & $-3 \%$ & -43.200 & $\mathrm{o}$ \\
\hline $\begin{array}{l}\text { Indikasi Nilai Tanah } / \mathrm{m}^{2} \\
\text { setelah penyesuaian (Rp) }\end{array}$ & 1.587 .600 & & 1.396 .800 & & \\
\hline Indikasi Nilai Pasar (Rp) & 1.492 .200 & & & & \\
\hline Pembulatan (Rp) & 1.490 .000 & & & & \\
\hline
\end{tabular}

Sumber: Data Primer, 2015

Dari Tabel 3 dapat diketahui indikasi nilai tanah sebesar Rp 178.200.000,oo, nilai ini merupakan harga penawaran setelah penyesuaian. Penyesuaian terhadap harga penawaran diberikan sebesar 10\% yang mencerminkan perbedaan antara harga penawaran dengan indikasi nilai pasarnya. Indikasi nilai tanah yang didapatkan kemudian dibagi dengan luas tanah untuk mengetahui indikasi nilai tanah $/ \mathrm{m}^{2}$. Selanjutnya dilakukan penyesuaian pada faktorfaktoryang berpengaruh terhadap indikasi nilai pasar objek penilaian, antara lain sebagai berikut.

1. Luas, Objek Pembanding II diberikan penyesuaian sebesar $-3 \%$ karena lebih luas dibanding dengan tanah objek penilaian. Pembanding I memiliki luas yang hampir sama dengan objek yang dinilai, sehingga tidak perlu penyesuaian. Baik objek penilaian maupun data pembanding sama-sama mempunyai peruntukan sebagai pemukiman, dimana untuk faktor luas tanah sangat berkaitan dengan peruntukannya. Dengan asumsi luas ideal untuk pemukiman adalah \pm 400 $\mathrm{m}^{2}$ maka luas Pembanding II lebih baik dari objek penilaian dan Pembanding I.

2. Status kepemilikan, status kepemilikan objek penilaian dan semua data pembanding adalah sama yaitu hak milik sehingga tidak perlu dilakukan penyesuaian.

3. Peruntukan, objek penilaian dan semua data pembanding dilihat peruntukannya secara riil di lapangan adalah sama yaitu sebagai pemukiman sehingga tidak perlu dilakukan penyesuaian.

4. Jarak dari Pasar Gamping, dilihat dari faktor jarak terhadap Pasar Gamping, Pembanding I diberikan penyesuaian sebesar-2\% dan Pembanding II diberikan penyesuaian sebesar o. Hal ini disebabkan karena Pembanding I terletak lebih dekat terhadap Pasar Gamping dibanding dengan objek penilaian, sedangkan jarak Pembanding II dan objek penilaian terhadap Pasar Gamping tidak jauh berbeda. Kedekatan dengan pusat perekonomian dalam hal ini Pasar Gamping akan berpengaruh terhadap harga tanah. Semakin dekat dengan pusat perekonomian maka harga tanah akan cenderung lebih tinggi.

5. Jarak dari Jalan Gamping-Sidoarum, Pembanding I, Pembanding II, dan objek penilaian berjarak relatif sama dekatnya dengan Jalan GampingSidoarum yang merupakan akses utama menuju ketiga tanah tersebut. Dalam penelitian ini diasumsikan bahwa jarak pada radius $300 \mathrm{~m}$ dari jalan utama dianggap tidak ada perbedaan jarak. Walaupun terdapat perbedaan jarak terhadap jalan utama namun tidak melebihi $300 \mathrm{~m}$ sehingga penyesuaian untuk Pembading I dan Pembanding II terhadap faktor jarak terhadap jalan utama adalah o.

Setelah dilakukan penyesuaian terhadap faktorfaktor yang dianggap mempengaruhi nilai maka dilakukan penghitungan indikasi nilai tanah $/ \mathrm{m}^{2}$ setelah penyesuaian. Indikasi nilai setelah penyesuaian ini didapatkan dengan cara mengalikan jumlah total penyesuaian dengan indikasi nilai tanah $/ \mathrm{m}^{2}$ dari masing-masing objek pembanding. Terhadap dua 
buah indikasi nilai tanah $/ \mathrm{m}^{2}$ setelah penyesuaian dari dua data pembanding dirata-rata untuk mendapatkan indikasi nilai pasar objek penilaian tersebut, yaitu sebesar Rp 1.490.00o,oo (satu juta empat ratus sembilan puluh ribu rupiah).

Menggunakan cara yang sama, kegiatan tersebut dilakukan terhadap 1 sampel objek penilaian yang lain. Rekapitulasi hasil penghitungan indikasi nilai pasar tanah dapat disajikan dalam Tabel 4 berikut.

Tabel 4. Rekapitulasi Hasil Penghitungan Indikasi Nilai Pasar

\begin{tabular}{|r|l|l|r|r|}
\hline No & $\begin{array}{c}\text { Objek } \\
\text { Penilaian }\end{array}$ & $\begin{array}{c}\text { Alamat Objek } \\
\text { Penilaian }\end{array}$ & $\begin{array}{c}\text { Luas Tanah } \\
\left(\mathrm{m}^{2}\right)\end{array}$ & $\begin{array}{l}\text { Indikasi Nilai } \\
\text { Pasar (Rp) }\end{array}$ \\
\hline 1 & I & Mejing Lor & 106 & $1.490 .000, \mathrm{oo}$ \\
\hline 2 & II & Mejing Lor & 411 & $1.730 .000, \mathrm{oo}$ \\
\hline 3 & III & Gamping Lor & 194 & $1.000 .000, \mathrm{oo}$ \\
\hline 4 & IV & Gamping Kidul & 98 & $1.410 .000, \mathrm{oo}$ \\
\hline 5 & V & Gamping Tengah & 211 & $5.550 .000, \mathrm{oo}$ \\
\hline 6 & VI & Depok & 207 & $2.480 .000, \mathrm{oo}$ \\
\hline 7 & VII & Mejing Kidul & 564 & $910.000, \mathrm{oo}$ \\
\hline 8 & VIII & Mejing Kidul & 478 & $850.000, \mathrm{oo}$ \\
\hline 9 & IX & Depok & 1238 & $1.500 .000, \mathrm{oo}$ \\
\hline 10 & X & Kalimanjung & 596 & $760.000, \mathrm{oo}$ \\
\hline 11 & XI & Mancasan & 300 & $570.000, \mathrm{oo}$ \\
\hline 12 & XII & Mancasan & 214 & $460.000, \mathrm{oo}$ \\
\hline
\end{tabular}

Sumber: Data primer diolah, 2015

Indikasi nilai pasar tanah yang dihitung merupakan hasil penilaian pada tahun 2015, sedangkan pembayaran BPHTB untuk tanah tersebut terjadi pada tahun 2014. Jika data 2014 digunakan untuk penilaian 2015 maka harus dilakukan penyesuaian waktu antara tanggal transaksi dengan tanggal penilaian. Hal ini dilakukan dengan menggunakan rumus $\mathrm{PV}=\mathrm{FV}(1+\mathrm{r})^{-\mathrm{n}}$ di mana:

$\mathrm{FV}=$ Future Value (nilai pada akhir tahun 2015)

$\mathrm{PV}=$ Present Value/nilai sekarang (nilai pada akhir tahun 2014)

r = suku bunga Bank Indonesia (pada akhir 2014 sebesar 7,75\%)

$\mathrm{n}$ = waktu (1 tahun)

Rumus tersebut mengasumsikan bahwa bunga digandakan hanya sekali dalam setahun, sehingga didapatkan indikasi nilai pasar tanah pada tahun 2014 yang dapat dilihat pada Tabel 5 .
Tabel 5. Indikasi Nilai Pasar Tanah, 2014

\begin{tabular}{|c|c|c|c|c|}
\hline No & $\begin{array}{c}\text { Objek } \\
\text { Penilaian }\end{array}$ & $\begin{array}{c}\text { Luas Tanah } \\
\left(\mathrm{m}^{2}\right)\end{array}$ & $\begin{array}{c}\text { Indikasi Nilai Pasar } \\
\text { pada Tahun } 2015(\mathrm{Rp})\end{array}$ & $\begin{array}{c}\text { Indikasi Nilai Pasar } \\
\text { pada Tahun } 2014 \text { (Rp) }\end{array}$ \\
\hline 1 & I & 106 & $1.490 .000,00$ & $1.380 .000,00$ \\
\hline 2 & II & 411 & $1.730 .000,00$ & $1.610 .000,00$ \\
\hline 3 & III & 194 & $1.000 .000,00$ & $930.000,00$ \\
\hline 4 & IV & 98 & $1.410 .000,00$ & $1.310 .000,00$ \\
\hline 5 & $\mathrm{~V}$ & 211 & $5.550 .000,00$ & $5.150 .000,00$ \\
\hline 6 & VI & 207 & $2.480 .000,00$ & $2.300 .000,00$ \\
\hline 7 & VII & 564 & 910.00o,oo & $840.000,00$ \\
\hline 8 & VIII & 478 & $850.000,00$ & $790.000,00$ \\
\hline 9 & IX & 1238 & $1.500 .000,00$ & $1.390 .000,00$ \\
\hline 10 & $\mathrm{X}$ & 596 & $760.000,00$ & $710.000,00$ \\
\hline 11 & $\mathrm{XI}$ & 300 & $570.000,00$ & $530.000,00$ \\
\hline 12 & XII & 214 & $460.000,00$ & $430.000,00$ \\
\hline
\end{tabular}

Sumber: Data primer diolah, 2015

\section{Tingkat Kesesuaian NPOP terhadap Nilai Pasar Tanah}

Pengukuran ini dilakukan dengan alat pengujian assessment sales ratio(ASR) untuk melihat rasio antara NPOP dengan nilai pasar tanahnya. ASR dalam penelitian ini merupakan perbandingan antara besaran NPOP yang digunakan untuk penetapan BPHTB dengan nilai pasar tanah tersebut, dapat dihitung dengan rumus: $\mathrm{ASR}=\frac{\mathrm{Ai}}{\mathrm{Si}}$ di mana:

ASR $=$ assessment sales ratio

$\mathrm{A}_{\mathrm{i}}=$ assessment value (dalam penelitian ini adalah NPOP)

$\mathrm{S}_{\mathrm{i}}=$ sales value (dalam hal ini adalah nilai pasar tanah)

Secara ringkas hasil penghitungan ASR pada objek penilaian dapat disajikan dalam Tabel 6 berikut.

Tabel 6. Hasil Penghitungan Asessment Sales Ratio

\begin{tabular}{|c|c|c|c|c|c|}
\hline No & $\begin{array}{c}\text { Objek } \\
\text { Penilaian }\end{array}$ & Lokasi & $\begin{array}{c}\mathrm{NPOP} / \mathrm{m}^{2} \\
(\mathrm{Rp})\end{array}$ & $\begin{array}{l}\text { Indikasi Nilai } \\
\text { Pasar (Rp) }\end{array}$ & ASR \\
\hline 1 & $\mathrm{I}$ & pemukiman & $755.000,00$ & $1.380 .000,00$ & 0,547 \\
\hline 2 & II & pemukiman & $750.000,00$ & 1.610.000,00 & 0,466 \\
\hline 3 & III & pemukiman & $515.000,00$ & 930.000,00 & 0,554 \\
\hline 4 & IV & pemukiman & $700.000,00$ & $1.310 .000,00$ & 0,534 \\
\hline 5 & $\mathrm{~V}$ & $\begin{array}{l}\text { perdaganga } \\
\mathrm{n}\end{array}$ & $920.000,00$ & $5.150 .000,00$ & 0,179 \\
\hline 6 & VI & pemukiman & 918.000,00 & $2.300 .000,00$ & 0,399 \\
\hline 7 & VII & pertanian & 401.000,00 & $840.000,00$ & 0,477 \\
\hline 8 & VIII & pertanian & 209.000,00 & $790.000,00$ & 0,265 \\
\hline 9 & IX & pertanian & 113.000,00 & $1.390 .000,00$ & 0,081 \\
\hline 10 & $\mathrm{X}$ & pertanian & $201.000,00$ & $710.000,00$ & 0,283 \\
\hline 11 & $\mathrm{XI}$ & pertanian & $269.000,00$ & $530.000,00$ & 0,508 \\
\hline 12 & XII & pemukiman & $299.000,00$ & $430.000,00$ & 0,695 \\
\hline \multicolumn{5}{|c|}{ Rata-rata } & 0,416 \\
\hline
\end{tabular}

Sumber: Data primer diolah, 2015

Dari Tabel 6 dapat diketahui bahwa tingkat ASR terendah terdapat pada Objek Penilaian IX yaitu sebesar 0,081. Dengan kata lain NPOP tanah ini sangat jauh dari nilai pasarnya karena perbandingan- 
nya hanya mencapai 8,1 persen. Tingkat ASR tertinggi terdapat pada Objek Penilaian XII yaitu sebesar o,695. NPOP tanah ini juga berada di bawah nilai pasarnya karena hanya berada pada tingkat 69,5 persen dari nilai pasarnya. Dari data tersebut dapat diketahui secara umum bahwa masyarakat Desa Ambarketawang melaporkan NPOP sebagai dasar penetapan BPHTB yang sangat rendah. Hal ini tentu saja dapat menimbulkan kerugian bagi pemerintah daerah atas hilangnya potensi penerimaan pajak dari sektor BPHTB.

Beberapa tahapan analisis ASR menurut Harjanto (2011: 122), adalah sebagai berikut.

1. Menghitung distribusi frekuensi dan histogramnya.

Pengukuran distribusi frekuensi dilakukan untuk mengetahui sebaran distribusi data ASR untuk seluruh wilayah dan dapat digunakan untuk menunjukkan jumlah/persentase dari objek yang dinilai dari berbagai tingkat rasio terhadap harga jualnya. Dari hasil pengukuran distribusi frekuensi dapat diketahui sebaran distribusi data ASR di Desa Ambarketawang dimana pada tingkat rasio 0,416-0,509 serta 0,509o,602 yang mempunyai frekuensi yang paling besar. Informasi ini menunjukkan bahwa NPOP yang dilaporkan belum mencerminkan nilai pasar yang sesungguhnya. Hasil pengukuran distribusi frekuensi data ASR di wilayah Desa Ambarketawang dapat dilihat pada Gambar 2.

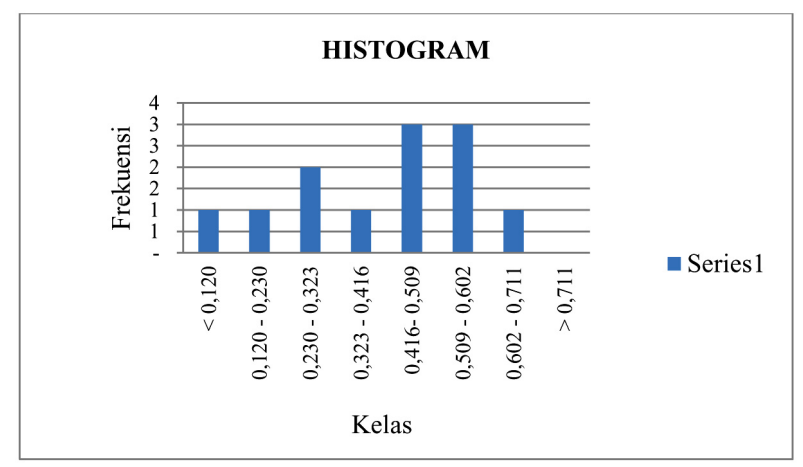

Gambar 2. Hasil Analisis Ditribusi Frekuensi. Sumber: Data primer diolah, 2015
2. Mengukur tendensi sentral (nilai tengah, ratarata, dan rata-rata tertimbang)

Pengukuran tendensi sentral dilakukan untuk mengetahui gambaran awal mengenai karakteristik ASR yang ada pada suatu wilayah berdasarkan pengujian statistik sederhana dari sampel. Pengukuran tendensi sentral terdiri dari median (nilai tengah), mean (nilai rerata), dan weighted mean (rerata tertimbang). Ringkasan hasil pengukuran tendensi sentral dapat dilihat pada Tabel 7 .

Tabel 7. Hasil Pengukuran Tendensi Sentral

\begin{tabular}{|c|r|r|l|}
\hline No & $\begin{array}{c}\text { NPOP } / \mathbf{m}^{2} \\
(\mathbf{R} \mathbf{)})\end{array}$ & INP (RP) & ASR \\
\hline 1 & 755.000 & 1.380 .000 & 0,547 \\
\hline 2 & 750.000 & 1.610 .000 & 0,466 \\
\hline 3 & 515.000 & 930.000 & 0,554 \\
\hline 4 & 700.000 & 1.310 .000 & 0,534 \\
\hline 5 & 920.000 & 5.150 .000 & 0,179 \\
\hline 6 & 918.000 & 2.300 .000 & 0,399 \\
\hline 7 & 401.000 & 840.000 & 0,477 \\
\hline 8 & 209.000 & 790.000 & 0,265 \\
\hline 9 & 113.000 & 1.390 .000 & 0,081 \\
\hline 10 & 201.000 & 710.000 & 0,283 \\
\hline 11 & 269.000 & 530.000 & 0,508 \\
\hline 12 & 299.000 & 430.000 & 0,695 \\
\hline Mean & & 0,416 \\
\hline \multicolumn{2}{|r|}{ Median } & 0,472 \\
\hline \multicolumn{2}{|l|}{ Weighted mean } & 0,348 \\
\hline Rasio Mean dengan Median & & 0,881 \\
\hline Rasio Mean dengan Weighted mean & \\
\hline
\end{tabular}

Sumber: Data Primer diolah, 2015.

Hasil pengukuran tendensi sentral menghasilkan nilai mean (rerata) sebesar o,416, median (nilai tengah) sebesar 0,472, dan weighted mean (rerata tertimbang) sebesar 0,348. Nilai mean sebesar o,416 mempunyai arti bahwa tingkat penetapan NPOP terhadap nilai pasar tanah di Desa Ambarketawang rata-rata adalah sebesar 41,6 persen.

3. Membandingkan tiap komponen hasil pengu-

kuran tendensi sentral

Rasio mean dengan median yang didapatkan sebesar o,881 mengindikasikan bahwa terjadi underassessment dalam penetapan NPOP sebagai dasar pengenaan BPHTB jika dibandingkan dengan nilai pasar tanah di lokasi penelitian, karena berdasarkan standar IAAO jika mean/median < o,9o (90\%) 
berarti terjadi under-assessment. Hal ini dapat dimaknai bahwa penetapan NPOP sebagai dasar pengenaan BPHTB di Desa Ambarketawang masih berada di bawah nilai pasar tanahnya.

Selain itu, indikator penting yang dapat diperoleh dari analisis tendensi sentral di atas adalah perbandingan antarkomponen yang digunakan untuk mengindikasikan terjadinya kecenderungan turun (regresivitas) dan kecenderungan naik (progresivitas). Rasio antara mean dan weighted mean menunjukkan hasil sebesar 1,193. Hal ini mengindikasikan terjadinya regresivitas dalam penetapan NPOP di Desa Ambarketawang karena hasilnya lebih besar dari 1,10 sesuai standar IAAO. Hal ini dapat dimaknai bahwa semakin tinggi nilai tanah, maka rasio antara penetapan NPOP dibandingkan dengan nilai pasarnya akan semakin menurun.

4. Mengukur variabilitas

Pengukuran tendensi sentral hanya mengindikasikan gambaran umum mengenai ASR terhadap tanah yang dinilai. Untuk mengukur performa ASR yang memadai maka perlu dilakukan pengukuran variabilitas yang meliputi koefisien variasi (coefficient of variation/COV) serta koefisien penyebaran (coefficient of dispersion/COD).

Menurut Rossini dan Kershaw (2006 dalam Novie, 2010: 6), koefisien variasi merupakan ukuran keseragaman dengan menggunakan mean. Semakin rendah COV maka akan semakin baik penentuan NPOP, berarti objek pajak yang serupa telah ditentukan NPOPnya pada suatu tingkat akurasi yang relatif sama. Aturan umum mengenai tingkat COV adalah bahwa keseragaman penentuan nilai dapat dikatakan baik jika COV sama atau kurang dari $25 \%$. COV dapat dicari dengan rumus:

$\operatorname{COV}=\frac{100}{\overline{\mathrm{A} / \mathrm{S}}} \sqrt{\left[\frac{\sum_{\mathrm{i}=1}^{\mathrm{n}}\left(\mathrm{A}_{\mathrm{i}} / \mathrm{S}_{\mathrm{i}}-\overline{\mathrm{A} / \mathrm{S}}\right)^{2}}{\mathrm{n}-1}\right]}$

di mana:

$\mathrm{A}_{\mathrm{i}} / \mathrm{S}_{\mathrm{i}}=$ tingkat assessment sales ratio pengamatan

$\overline{\mathrm{A} / \mathrm{S}}=$ rerata pengamatan

$\mathrm{n}=$ jumlah pengamatan
Selain itu, pengukuran variabilitas bisa diketahui melalui pengukuran koefisien penyebaran (coefficient of dispersion/COD). COD digunakan untuk mengukur variasi harga jual tanah terhadap assessment value. Rossini dan Kershaw (2006 dalam Novie, 2010: 6) mengungkapkan bahwa, koefisien penyebaran adalah ukuran keseragaman menggunakan nilai median. Semakin rendah COD maka akan semakin baik dalam penentuan NPOP. Secara matematis COD dapat dirumuskan:

$\widetilde{\mathrm{COD}}=\frac{100}{\widetilde{\mathrm{A}} / \mathrm{S}}\left(\frac{\sum_{\mathrm{i}=1}^{\mathrm{n}}\left|\mathrm{A}_{\mathrm{i}} / \mathrm{S}_{\mathrm{i}}-\widetilde{\mathrm{A}} / \mathrm{S}\right|}{\mathrm{n}-1}\right)$

di mana:

$\mathrm{A}_{\mathrm{i}} / \mathrm{S}_{\mathrm{i}}=$ tingkat assessment sales ratio pengamatan

$\widetilde{\mathrm{A}} / \mathrm{S}=$ nilai tengah pengamatan

$\mathrm{n}=$ jumlah pengamatan

[ ] = nilai absolut

Tabel 8. Penghitungan Variabilitas

\begin{tabular}{|c|c|c|c|c|c|c|c|c|}
\hline No. & $\mathrm{NPOP} / \mathrm{M}^{2}$ & INP & ASR & $\begin{array}{c}\text { ASR - } \\
\text { MEDIAN }\end{array}$ & $\begin{array}{c}\mid \text { ASR- } \\
\text { MEDIAN }\end{array}$ & $\begin{array}{l}\text { ASR - } \\
\text { MEAN }\end{array}$ & $\begin{array}{l}\text { |ASR - } \\
\text { MEAN | }\end{array}$ & $\begin{array}{c}\mid \text { ASR- } \\
\text { MEAN } \mid)^{2}\end{array}$ \\
\hline 1 & 755.000 & 1.380 .000 & 0,547 & 0,075 & 0,075 & 0,131 & 0,131 & 0,017 \\
\hline 2 & 750.000 & 1.610 .000 & 0,466 & $-0,006$ & $-0,006$ & 0,050 & 0,050 & 0,003 \\
\hline 3 & 515.000 & 930.000 & 0,554 & 0,082 & 0,082 & 0,138 & 0,138 & 0,019 \\
\hline 4 & 700.000 & 1.310 .000 & 0,534 & 0,063 & 0,063 & 0,119 & 0,119 & 0,014 \\
\hline 5 & 920.000 & 5.150 .000 & 0,179 & $-0,293$ & 0,293 & $-0,237$ & 0,237 & 0,056 \\
\hline 6 & 918.000 & 2.300 .000 & 0,399 & $-0,072$ & $-0,072$ & $-0,017$ & 0,017 & 0,000 \\
\hline 7 & 401.000 & 840.000 & 0,477 & o,oo6 & $-0,006$ & 0,062 & 0,062 & 0,004 \\
\hline 8 & 209.000 & 790.000 & 0,265 & $-0,207$ & 0,207 & $-0,151$ & 0,151 & 0,023 \\
\hline 9 & 113.000 & 1.390 .000 & 0,081 & $-0,390$ & 0,390 & $-0,334$ & 0,334 & 0,112 \\
\hline 10 & 201.000 & 710.000 & 0,283 & $-0,189$ & 0,189 & $-0,133$ & 0,133 & 0,018 \\
\hline 11 & 269.000 & 530.000 & 0,508 & 0,036 & $-0,036$ & 0,092 & 0,092 & 0,008 \\
\hline 12 & 299.000 & 430.000 & 0,695 & 0,224 & 0,224 & 0,280 & 0,280 & 0,078 \\
\hline \multicolumn{5}{|c|}{ JUMLAH } & 1,403 & & & 0,352 \\
\hline \multicolumn{4}{|c|}{ MEAN } & 0,416 & & & & \\
\hline \multicolumn{4}{|c|}{ MEDIAN } & 0,472 & & & & \\
\hline \multicolumn{4}{|c|}{ WMEAN } & 0,348 & & & & \\
\hline \multicolumn{4}{|c|}{ RASIO MEAN DGN MEDIAN } & 0,881 & & & & \\
\hline \multicolumn{4}{|c|}{ RASIO MEAN DGN WMEAN } & 1,193 & & & & \\
\hline \multicolumn{4}{|c|}{ COD MEDIAN } & 27,045 & & & & \\
\hline \multicolumn{4}{|c|}{ COV MEAN } & 43,041 & & & & \\
\hline
\end{tabular}

Sumber: Data Primer diolah, 2015.

Dari Tabel 8 dapat dilihat hasil perhitungan COV sebesar 43,041, lebih tinggi dari standar yang ditetapkan IAAO yaitu maksimal 20 persen. COV sebesar 43,041 persen menunjukkan kecenderungan variabilitas yang tinggi. Hal ini bermakna bahwa hasil assessment di Desa Ambarketawang memiliki variasi rasio yang tinggi atau tidak memiliki keseragaman tingkat rasio yang baik. 
Hasil perhitungan COD yang telah dilakukan menghasilkan nilai COD sebesar 27,045. Standar level assessment dari IAAO 2013 menyebutkan bahwa nilai COD yang menunjukkan keseragaman assessment yang baik terhadap sekelompok tanah tanah kosong (vacant land) adalah minimal 5 persen dan maksimal 25persen. COD yang dihasilkan sebesar 27,045 persen tidak menunjukkan keseragaman yang baik dalam penetapan NPOP untuk BPHTB di Desa Ambarketawang. Hal ini berarti dalam satu kelompok/strata tanah tidak ditetapkan assessment yang seragam sehingga dapat disimpulkan terdapat ketidakadilan secara horizontal dalam penetapan NPOP sebagai dasar pengenaan BPHTB di Desa Ambarketawang. 5. Evaluasi Hasil ASR

Evaluasi hasil analisis ASR ini bertujuan untuk melihat lebih jauh kemaknaan secara statistik analisis yang telah dilakukan. Evaluasi ini meliputi empat uji sebagai berikut.

a. Uji Normalitas Distribusi

Uji normalitas distribusi ASR untuk menguji apakah assessment sales ratio berada pada kondisi atau memenuhi distribusi normal. Hal ini penting dilakukan manakala salah satu koefisien variasi digunakan untuk ukuran utama variabilitas assessment. Jika assessment sales ratio terdistribusikan dengan normal, COV yang dihasilkan memberikan gambaran yang cukup valid mengenai variabilitas assessment sales ratio yang dihasilkan, dan sebaliknya (Harjanto, 2010: 129). Pengujian normalitas distribusi pada penelitian ini dilakukan dengan uji chi-square $\left(\mathrm{X}_{2}\right)$ yang menghasilkan nilai $\mathrm{X}_{2}$ sebesar 2,500. Nilai $\mathrm{X}_{2}$ tabel pada 7 degree of freedom (df) dan 95\% level of convidence yaitu pada 14,070. Karena harga $\mathrm{X}_{2}$ hitung $<\mathrm{X}_{2}$ tabel maka distribusi data assessment sales ratio pada 12 sampel dapat dinyatakan berdistribusi normal. Hal ini bermakna bahwa COV yang dihasilkan memberikan gambaran yang cukup valid mengenai variabilitas assessment sales ratio dalam hasil penelitian ini.

b. Uji Aras Nilai (Testing The Level of Assessment)
Uji aras nilai dilakukan untuk melihat apakah nilai assessment berada pada persentase tertentu (sesuai yang telah ditetapkan) terhadap nilai pasar. Hal ini penting dilakukan karena salah satu tugas penilai adalah menjaga aras nilai yang dihasilkan berada pada tingkat tertentu yang ditetapkan regulasi/kebijakan dibandingkan dengan nilai pasarnya (Harjanto, 2010: 132).

Pengujian aras nilai ini dilakukan dengan menggunakan uji-t yang menghasilkan nilai $t$ sebesar -11,291. Nilai kritis t untuk pengujian 2 sisi dengan df 11 dan tingkat keyakinan 95\% adalah \pm 2,201. Karena t hitung $>$ t tabel atau terletak di daerah penolakan Ho sehingga dapat dimaknai bahwa rerata ASR tidak dinilai sesuai seratus persen nilai pasar. Rerata ASR yang belum mencerminkan nilai pasar yang sesungguhnya dapat menimbulkan kerugian bagi pemerintah daerah atas hilangnya potensi penerimaan pajak dari sektor BPHTB.

c. Uji Beda Aras Nilai Antarkelompok Tanah Pengujian beda aras nilai antarkelompok tanah diperlukan untuk menjaga kekonsistenan dalam penetapan nilai. Hal ini dilakukan karena keadilan dalam penetapan nilai tidak hanya dilihat dari variabilitas nilai antarjenis penggunaan, antarkawasan, atau strata tanah, tetapi tiap kelompok (jenis penggunaan/kawasan) harus dinilai pada aras yang sama terhadap nilai pasarnya (Harjanto, 2010: 134).

Jenis uji yang digunakan untuk menguji perbedaan aras nilai assessment antar kelompok dalam penelitian iniadalah Uji Kruskal-Wallis. Uji ini dipilih untuk mengetahui ada tidaknya perbedaan aras nilai pada tiga kelompok tanah yang diteliti yaitu kelompok tanah pemukiman (kelompok A), perdagangan (kelompok B), dan pertanian (kelompok C). Kelompok ini dikategorikan berdasarkan jenis penggunaan tanah pada objek penilaian .

Hipotesis dalam penghitungan ini adalah: Ho: kelompok A,B, C dinilai pada tingkat 
persentase yg sama terhadap nilai pasar

Hi: kelompok A,B, C dinilai pada tingkat persentase yg tidak sama terhadap nilai pasar.

Secara ringkas penghitungan hasil Uji KruskalWallis $(\mathrm{H})$ yang didapatkan adalah sebesar 5,459. Dengan jumlah kelompok tanah adalah tiga (3), maka derajad kebebasan (degree of freedom/df) adalah dua (2). Karena sangat mirip dengan chikuadrat maka menggunakan chi-kuadrat untuk membuat keputusan berdasarkan tabel nilai kritis chi-kuadrat. Nilai kritis ( $\mathrm{H}$ tabel) untuk $\mathrm{df}=\mathbf{2}$ dan tingkat resiko o,05 adalah 5,991. Nilai H hitung < $\mathrm{H}$ tabel maka Ho diterima. Hal ini berarti bahwa tidak terdapat perbedaan aras nilai di antara tiga kelompok tersebut, atau dengan kata lain kelompok A, B, C dinilai pada tingkat persentase yang sama dengan nilai pasar.

d. Uji Regresivitas/Progresivitas

Indikasi awal terhadap kecenderungan regresivitas dan progresivitas sebagaimana dikemukakan sebelumnya dapat dideteksi dari perbandingan antar rerata (mean) dan rerata tertimbang (weighted mean). Jika perbandingan tersebut lebih besar dari 1,10o diindikasikan terdapat kecenderungan regresivitas. Sebaliknya jika perbandingan tersebut lebih rendah dari o,900 maka diindikasikan terjadinya kecenderungan progresivitas. Telah dikemukakan sebelumnya pula bahwa terjadi kecenderungan regresivitas di Desa Ambarketawang, dimana tanah yang mempunyai nilai jual rendah dinilai pada persentase yang lebih tinggi terhadap nilai pasarnya dibandingkan dengan tanah yang memiliki nilai jual lebih tinggi.

Untuk menguji kecenderungan ini dapat dilakukan melalui analisis regresi dan uji Spearman Rank Test. Uji penjenjangan Spearman (Spearman Rank Test) dilakukan untuk mengetahui apakah nilai ASR memiliki hubungan yang bebas (independent) atau tidak bebas (dependent) terhadap indikasi nilai pasar tanah (INP). Hipotesisnya adalah sebagai berikut.
Ho: ASR memiliki hubungan yang bebas terhadap INP.

Hi: ASR memiliki hubungan yang tidak bebas terhadap INP.

Secara ringkas didapatkan nilai t sebesar -1,552, nilai t yang negatif mengindikasikan terjadinya regresivitas. Untuk mengetahui tingkat signifikansinya, maka nilai t hitung dibandingkan dengan nilai t tabel. Dengan $\mathrm{df}=10$ dan taraf kesalahan 5\% didapatkan nilai t tabel sebesar $\pm 2,228$. Karena nilai $t$ tabel $>t$ hitung, sehingga Ho diterima. Artinya, secara statistik ASR memiliki hubungan yang bebas terhadap INP. Dapat disimpulkan dari hasil uji ini bahwa terjadi regresivitas yang tidak signifikan.

\section{E. Penutup}

\section{Simpulan}

1. Penetapan NPOP sebagai dasar pengenaan BPHTB di Desa Ambarketawang Kecamatan Gamping Kabupaten Sleman masih relatif rendah dibandingkan dengan nilai pasar tanahnya. Berdasarkan pengukuran tendensi sentral dapat disimpulkan terjadi under-assessment dalam penetapan NPOP sebagai dasar pengenaan BPHTB karena berada jauh di bawah nilai pasar tanahnya. Hal ini menunjukkan belum optimalnya penetapan NPOP sebagai dasar penentuan BPHTB yang berarti masih ada potensi pajak yang bisa digali dari sektor BPHTB untuk lebih meningkatkan PAD. Selain itu, dideteksi terjadi kecenderungan regresivitas yang dapat dimaknai bahwa di Desa Ambarketawang tanah yang mempunyai nilai jual rendah dinilai pada persentase yang lebih tinggi terhadap nilai pasarnya dibandingkan dengan tanah yang memiliki nilai jual lebih tinggi.

2. Variabilitas dalam penetapan NPOP sebagai dasar penentuan BPHTB di Desa Ambarketawang sangat tinggi atau tidak menunjukkan keseragaman yang baik. Hal ini berarti dalam satu kelompok/strata tanah tidak ditetapkan assess- 
ment yang seragam sehingga dapat disimpulkan terdapat ketidakadilan secara horizontal dalam penetapan NPOP sebagai dasar pengenaan BPHTB di Desa Ambarketawang.

\section{Saran}

1. Adanya ketidakseragaman dalam penetapan NPOP sebagai dasar penentuan BPHTB di Desa Ambarketawang menyebabkan ketidakadilan di masyarakat. Hal ini dapat dijadikan dasar pertimbangan bagi Pemda Kabupaten Sleman untuk menetapkan acuan NPOP yang lebih mendekati nilai pasar dan selalu diup-date secara berkala sesuai dengan perkembangan pasar.

2. Perlu adanya proses validasi dan verifikasi lapangan untuk setiap pembayaran BPHTB oleh Dispenda Kabupaten Sleman. Validasi dilakukan untuk memastikan bahwa pembayaran BPHTB masuk ke kas pemerintah daerah, di mana tarifnya benar dan perhitungannya juga benar. Verifikasi lapangan dilakukan untuk memastikan keadaan objek yang diajukan adalah sesuai dengan kondisi di lapangan.

3. BPHTB merupakan pajak yang pembayarannya berdasar self assessment yang memerlukan kesadaran para pihak untuk melaporkannya. Perlu upaya memberikan sosialisasi kepada masyarakat agar masyarakat termotivasi melaporkan NPOP sesuai dengan harga transaksi sebenarnya. Perlu ditanamkan secara luas bahwa pajak yang dibayarkan merupakan aset daerah yang nantinya akan kembali kepada masyarakat untuk meningkatkan kesejahteraan masyarakat.

\section{Daftar Pustaka}

Badan Pusat Statistik Kabupaten Sleman 2014, Sleman dalam Angka 2013, Yogyakarta.

Dorchester Jr, John, 2011, "Market Value, Fair Value, and Duress." Journal of Property Investment \& Finance, Vol. 29, No. 4/5, pg. 428447. Tersedia di http:// www.emeraldinsight.com/doi/pdfplus/ 10.1108/14635781111150321, diakses pada 16
Januari 2015.

Elriza, Paat, 2013, “Tingkat Akurasi Penetapan NJOP Bumi terhadap Nilai Pasar dengan Metode ASR di Kecamatan Sario Kota Manado Tahun 2012." Jurnal EMBA, Vol. 1 No 4, hal 1375-1385. Tersedia di http:// d own load.portalgaruda.org / article.php?article $=109185 \&$ val $=1025$, diakses pada 18 Februari 2015.

Harjanto, Budi, 2011, Teori dan Berbagai Model Aplikasi Penilaian Massal, BPFE,Yogyakarta.

Hartoyo,1998, Assessment sales ratio Suatu Alat Pengukur Kinerja Penilaian Dalam

Pelaksanaan PBB, Modul Penilaian II, Jakarta.

Hodge, Timothy R, Skidmore, Mark, Sands, Gary, and McMillen, Daniel, 2013, Assessment Inequity in Declining Housing Market: The Case of Detroit, Center for Economic Studies and Ifo Institute, Ozyegin Munic.

International Association of Assessing Officers (IAAO), 2013, Standar on Ratio Studies, Kansas City.

Kuswanto, Dedi, 2014, "Akurasi Nilai Perolehan Objek Pajak (NPOP) sebagai dasar Pengenaan Pajak Bea Perolehan Hak atas Tanah dan Bangunan (BPHTB) terhadap Nilai Pasar (Studi di Kecamatan Purwokerto Timur, Banyumas).” Tesis tidak diterbitkan, Program Pasca Sarjana UGM, Yogyakarta.

Novie dan Sandra, Amalia, 2010, "Analisis Tingkat Akurasi Penetapan NJOP terhadap Nilai Pasar dengan Metode ASR (Studi Kasus di Kecamatan Kelapa Gading Kotamadya Jakarta Utara)." Skripsi tidak diterbitkan, Program Sarjana, Institut Bisnis dan Informatika Indonesia, Jakarta. Tersedia di http:// eprints.unisbank.ac.id/182/1/artikel-20.pdf, diakses pada 18 Februari 2015.

Payton, Seth B, 2010, The Impact of Property Assessment Standards on Property Tax Burden: An Examination of Systematic Bias in a Market Value Versus a Non-Market Value Assessment Standars, Indiana University-Purdue University, Indianapolis.

Pemerintah Daerah Sleman 2010,Peraturan Daerah Kabupaten Sleman Nomor 14 Tahun 
2010 tentang BPHTB, Sleman.

------, 2013, Rencana Kerja Pengembangan Daerah/RKPD Kabupaten Sleman Tahun 2013, Sleman.

Strauss, Robert P, 2013, A Sales Ratio Study of the City of Philadelpia's 2013 Cartified and 2014 Proposed Real Estate Assessments, Carnegie Mellon University, Pittsburgh, Pennsylvania.

Sutrisna Agung, Dedy, 2014, "Tingkat Keakuratan Nilai Perolehan Objek Pajak (NPOP) terhadap Nilai Pasar Tanah sebagai Dasar Optimalisasi Penerimaan Pendapatan Asli Daerah (PAD) dari Sektor Bea Perolehan Hak atas Tanah dan Bangunan (BPHTB) (Studi: Tanah di Kota Denpasar tahun 2013)." Tesis tidak diterbitkan, Program Pasca Sarjana, UGM. Yogyakarta.

Undang-Undang Republik Indonesia Nomor 28 Tahun 2009 tentang Pajak Daerah Dan Retribusi Daerah, Jakarta. 

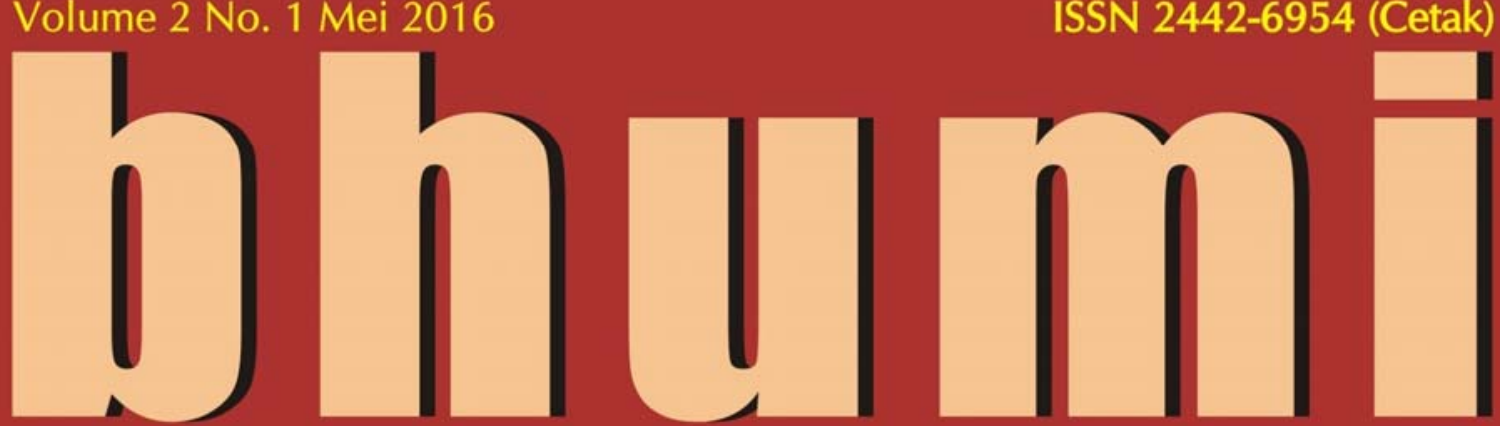

\section{Jurnal Agraria dan Pertanahan}

Penataan Hubungan Hukum dalam Penguasaan dan Pemilikan serta Penggunaan dan Pemanfaatan Sumber Daya Agraria (Studi Awal Terhadap Konsep Hak Atas Tanah dan Ijin Usaha Pertambangan)

Oloan Sitorus

$1-11$

Politik Hukum Pengelolaan Perkebunan

Berbasis Prinsip-prinsip Hak Asasi Manusia (HAM)

Randy Pradityo 12-18

Integrasi Penataan Pertanahan dalam Kerangka Penataan Wilayah Pesisir dan Lahan Atas Terpadu

Waryanta 19-30

Bertani Diantara Himpitan Tambang (Belajar dari Petani Kutai Kartanegara) M. Nazir Salim 31-47
Integrasi Sistem Informasi Pertanahan dan Infrastruktur Data Spasial dalam Rangka Perwujudan One Map Policy

Sukmo Pinuji

48-64

Computer Assisted Mapping (CAM) Potensi Lahan Pertanian Pangan Berkelanjutan Guna Mendukung Perlindungannya

\section{Senthot Sudirman}

$65-80$

Kajian Upaya Pengendalian Penggunaan

Tanah di Kabupaten Temanggung Provinsi Jawa Tengah

Slamet Muryono

81-95

Assessment Sales Ratio, Suatu Alat Pengukur Kinerja Penetapan NPOP (Studi di Desa Ambarketawang, Sleman) Asih Retno Dewi 96-108

Review Buku: Mollo, Pembangunan dan Perubahan Iklim. Usaha Rakyat Memulihkan Alam yang Rusak Anna Mariana 109-112

\begin{tabular}{|c|c|c|c|c|c|}
\hline BHUMI & Volume 2 & Nomor 1 & $\begin{array}{c}\text { Halaman } \\
1-113\end{array}$ & $\begin{array}{c}\text { Yogyakarta } \\
\text { Mei 2016 }\end{array}$ & $\begin{array}{c}\text { ISSN } \\
2442-6954\end{array}$ \\
\hline
\end{tabular}

